\title{
Estimating Onset of Precipitation of Dissolved Asphaltene in the Solution of Solvent + Precipitant Using Artificial Neural Network Technique
}

\author{
Amir H. Mohammadi and Dominique Richon*
}

Mines Paris, ParisTech, CEP-TEP, CNRS FRE 2861, 35 rue Saint Honoré, 77305 Fontainebleau, France

\begin{abstract}
Asphaltene precipitation is traditionally modeled using polymer solution theories or cubic equations of state. We propose another approach based on artificial neural network technique to model onset of precipitation of dissolved asphaltene in the solution of solvent + precipitant. A mathematical model based on feed-forward artificial neural network technique, which takes advantage of a modified Levenberg-Marquardt optimization algorithm, has been used to model onset of precipitation of dissolved asphaltene in the solvent + precipitant solution. The experimental data reported in the literature have been used to develop this model. The acceptable agreement between the results of this model and experimental data demonstrates the capability of the neural network technique for estimating onset of precipitation of dissolved asphaltene in the solution of solvent + precipitant.
\end{abstract}

Keywords: Asphaltene, solvent, precipitant, artificial neural network, modeling, precipitation.

\section{INTRODUCTION}

One serious problem that can affect oil production, transportation and processing, is asphaltene precipitation. Asphaltenes are the toluene / benzene soluble fractions that precipitate from oil when an excess (25 to 40 times) of n-heptane / $\mathrm{n}$-pentane is mixed with oil after waiting for at least four hours before filtering [1]. Asphaltene precipitation causes fouling in the reservoir, in the well, in the pipeline and in the production and processing facilities [1-35]. Asphaltene phase behavior has therefore been the subject of numerous theoretical studies [1-35]. The lack of suitable characterization parameters is one of the difficulties encountered in describing the phase behavior of asphaltene-containing systems, because asphaltenes are not well-identified components/ mixtures $[1,7]$. They consist of several polar components of aromatic nature with high molecular weights $[1,7]$. In the majority of cases, the complexity of the asphaltene fraction leads to the assumption that the asphaltenes can be regarded as one single pseudo-component (monodisperse) $[1,7]$.

The traditional models reported in the literature typically use polymer solution theories (e.g. Scatchard-Hildebrand [7], Flory-Huggins [7, 36], and Scott-Magat [37] polymer solution theories) to model phase behavior of asphaltenecontaining fluids $[1,2,5,7,8,14,20-23]$. In addition to these models, there are also other models, which are based on cubic equations of state [17, 24]. New thermodynamic models have recently been developed, which can take into account the micellar / aggregation natures of asphaltenes [5, $13,16,26-31]$.

In order to examine the capabilities of the models reported in the literature to predict asphaltene phase behavior in dilute systems, Cimino et al. $[2,14]$ performed some tests

*Address correspondence to this author at the Mines Paris, ParisTech, CEPTEP, CNRS FRE 2861, 35 rue Saint Honoré, 77305 Fontainebleau, France; Tel: +(33) 1646949 65; Fax: +(33) 1646949 68;

E-mail: richon@ensmp.fr
(Table 1) to find onset of precipitation of dissolved asphaltenes in various solutions with different ratios of solvent and precipitant and indicated that the precipitated asphaltene does dissolve in appropriate solvent and the ratio of "solvent mass per asphaltene mass" and "precipitant mass per asphaltene mass" is approximately linear and independent of the asphaltene concentration at onset of asphaltene precipitation $[2,14]$. They showed that the capability of colloidal model [25] and traditional Flory-Huggins [36] based models [8, 20] to re-produce the observed behavior is poor, mainly because most of the models reported in the literature assume that the precipitated phase consists of asphaltene only and the presence of non-asphaltene components in the precipitated phase is normally ignored. Cimino et al. [2, 14] employed the Flory-Huggins polymer solution theory [36] and assumed that the precipitated phase contains not only asphaltene but also a fraction of non-asphaltene components. They showed that their proposed model $[2,14]$ can better predict the phase behavior of dissolved asphaltenes in the solutions of solvents and precipitants and none of the literature models is capable of predicting this behavior satisfactorily.

The objective of this work is to show the capability of Artificial Neural Network $(A N N)$ technique, as an alternative model, to estimate onset of precipitation of dissolved asphaltene in the solvent + precipitant solutions. To our knowledge, this method has not previously been reported for phase behavior modeling of asphaltene containing systems. Among various $A N N$ s models reported in the literature, the feedforward (back propagation) neural network $(F N N)$ model along with a modified Levenberg-Marquardt optimization algorithm $[40,41]$ is used, which is known to be effective to represent the nonlinear relationships between variables in complex systems and can be regarded as a large regression method between input and output variables [42-48]. To develop this model, the experimental data reported by Cimino et al. $[2,14]$ are used. It is shown that the data reported by Cimino et al. $[2,14]$ are well represented by the $A N N$ model demonstrating the capability of this technique to estimate 
Table 1. Experimental Values for Mass Fractions of Components in the Synthetic Mixtures of Asphaltene + Solvent + Precipitant at Onset of Asphaltene Precipitation Measured at 298.15 K and 0.1 MPa [14]

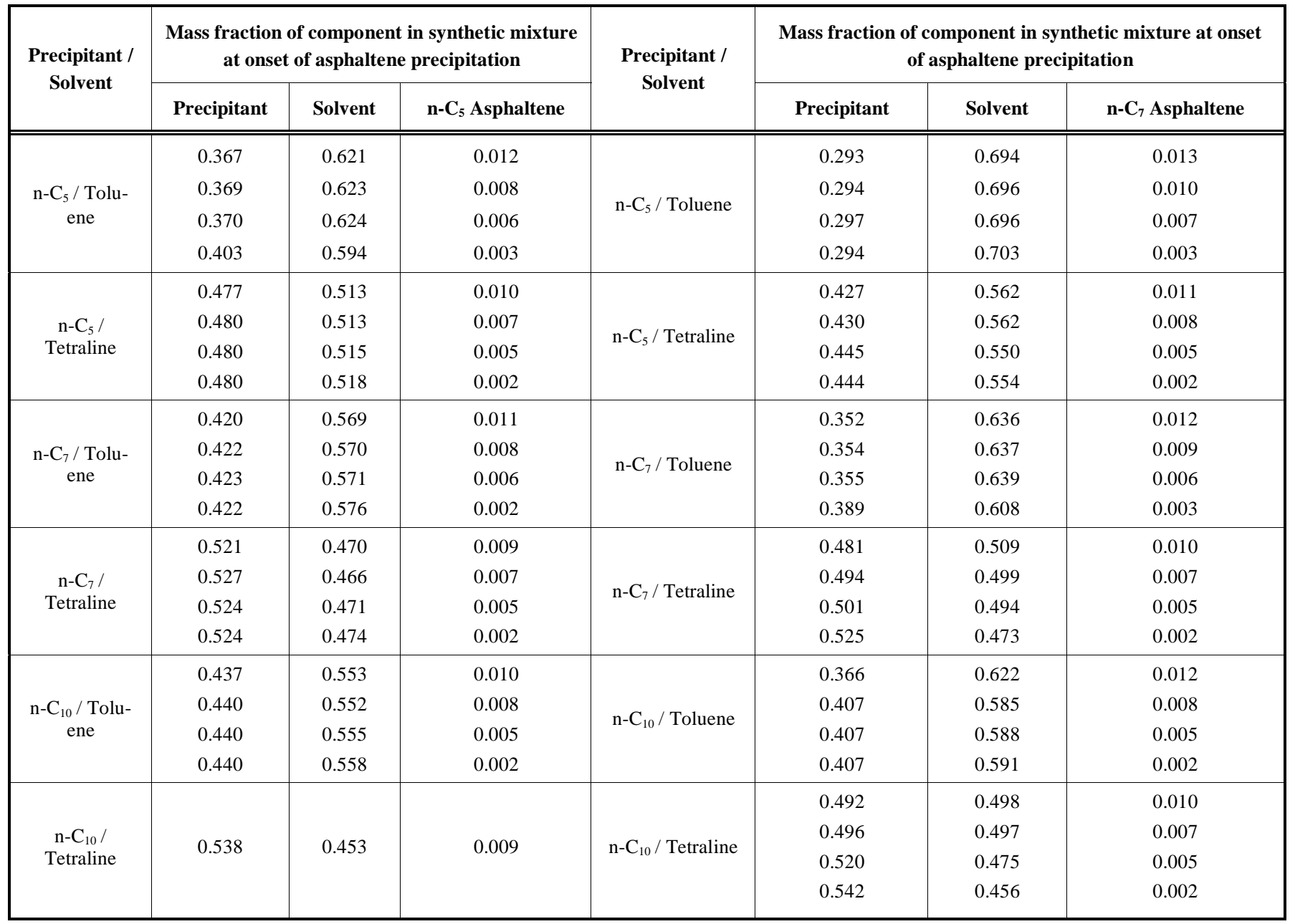

onset of precipitation of dissolved asphaltene in the solutions of solvent + precipitant.

\section{THERMODYNAMIC MODELS TO DETERMINE ONSET OF PRECIPITATION OF DISSOLVED ASPHALTENE IN THE SOLVENT + PRECIPITANT SOLUTION [35]}

As mentioned earlier, Cimino et al. [2, 14] employed a more correct application of the Flory-Huggins polymer solution theory [36] to represent phase behavior of dissolved asphaltenes in the solvent + precipitant solutions. Different from the previous models based on Flory-Huggins polymer solution theory [36], which assume the precipitated phase forms pure asphaltene, it is assumed that on phase separation, not a pure asphaltene phase nucleates but a phase concentrated in asphaltenes containing also a fraction of solvent $[2,14]$. Considering typical asphaltene volume fraction, $\Phi_{a}$, in oil system (which is estimated in the range of $10^{-2}$ to $10^{-3}$ with asphaltene weight percent from 1 to $10[2,14])$ the oil is assumed safely to be pure maltene (asphaltene free oil), that is $\Phi_{a}=0[2,14]$. Such an assumption leads to the following final equation $[2,14,35]$ :

$\ln \left[1-\Phi_{\mathrm{a}}{ }^{\prime}\right]+\left(1-\frac{V_{m}}{V_{a}}\right) \Phi_{\mathrm{a}}{ }^{\prime}+\chi \Phi_{\mathrm{a}}{ }^{2}=0$ where the prime represents the asphaltene-rich phase and $\Phi_{a}$ is the volume fraction of asphaltene in asphaltene-rich phase. $V_{m}$ and $V_{a}$ are molar volumes of maltene and asphaltene, respectively. $\chi$ stands for interaction parameter between asphaltene and maltene and is given by the following equation $[2,8,14,35]$ :

$\chi=\frac{V_{m}\left[\left(\delta_{m}-\delta_{a}\right)^{2}\right]}{R T}$

where $\delta_{m}$ and $\delta_{a}$ are solubility parameters (the square root of the internal energy of vaporization per molecular volume) for the maltene and the asphaltene, respectively [35]. $R$ and $T$ stand for universal gas constant and temperature respectively.

In the above equation [35, 37-39]

$\Phi_{a}=\frac{x_{a} V_{a}}{x_{a} V_{a}+x_{m} V_{m}}$

or

$\Phi_{a}=\frac{w_{a} / \rho_{a}}{w_{a} / \rho_{a}+w_{m} / \rho_{m}}$ 
where $w_{a}$ and $w_{m}$ are the weight fractions of asphaltene and maltene, respectively and $\rho_{a}$ and $\rho_{m}$ represent the mass densities of asphaltene and maltene, respectively. $x_{\mathrm{a}}$ and $x_{\mathrm{m}}$ stand for mole fractions of asphaltene and maltene, respectively.

A similar model based on the Scott-Magat polymer solution theory [37] can also be obtained [35]:

$\ln \left[1-\Phi_{\mathrm{a}}{ }^{\prime}\right]+\Phi_{\mathrm{a}}{ }^{\prime}+\chi \Phi_{\mathrm{a}}{ }^{2}=0$
Equation (5) is similar to equation (1) (Considering the ratio $\frac{V_{m}}{V_{a}}$ in equation (1) is negligibly small compared to unity, and therefore it may be neglected) [35].

According to the model of Cimino et al. [2, 14], $\delta_{a}$ is assumed to be independent of pressure, and $\Phi_{a}$ is assumed to be constant. The parameters $\Phi_{a}$ and $\delta_{\mathrm{a}}$ are regressed from

Table 2. Experimental Values [14] and the Values Obtained Using the ANN Model for (Mass of Precipitant/ Mass of Asphaltene) in Synthetic Mixtures of Asphaltene + Solvent + Precipitant at Onset of Asphaltene Precipitation at 298.15 K and 0.1 MPa

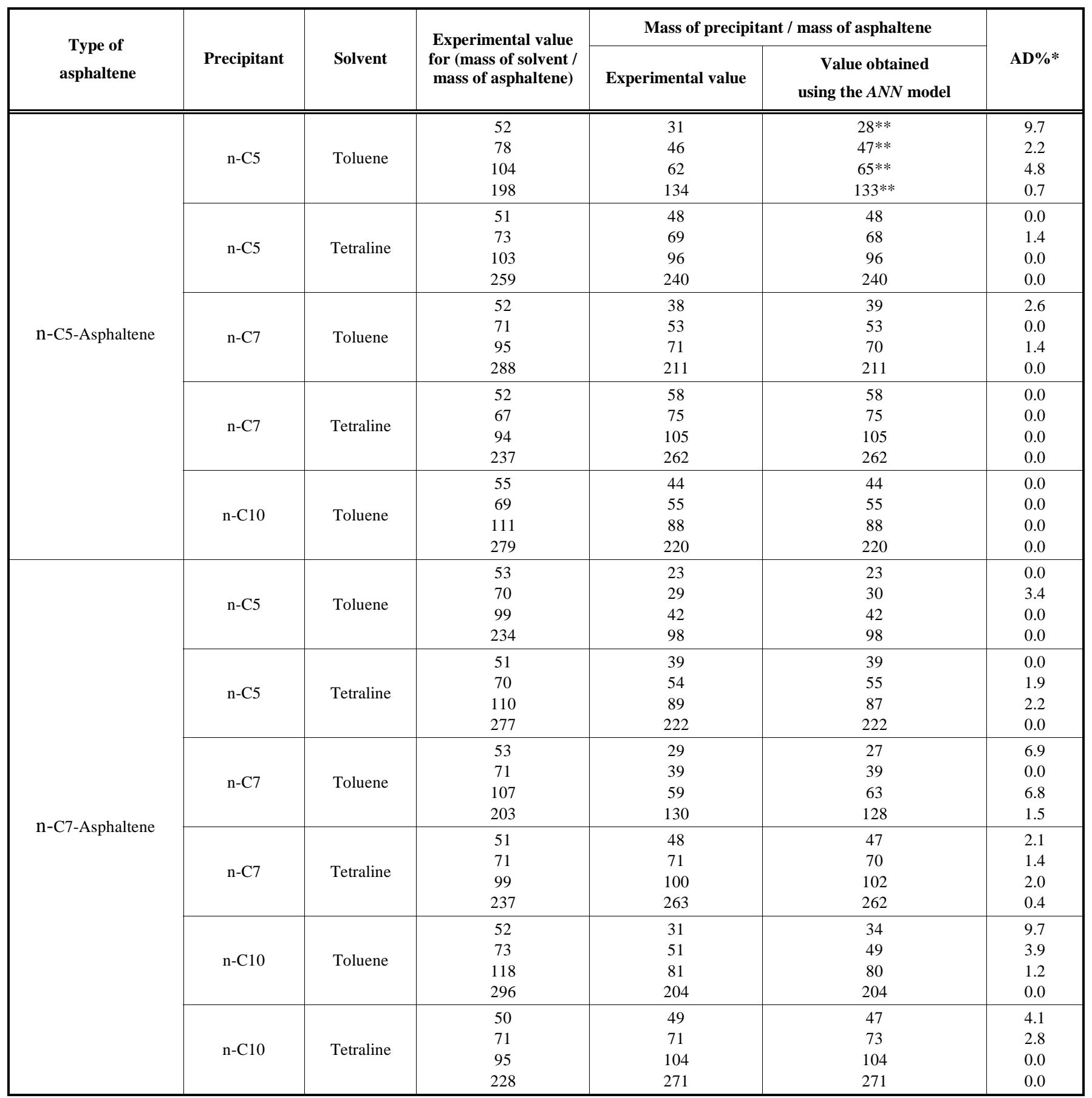

*: Absolute deviation $\left(A D=\left|\frac{\text { experimental value }- \text { predicted } / \text { calculated value }}{\text { experimental value }}\right|\right.$ )

**: Validates values. The remaining data in this table were used for training (and testing). 


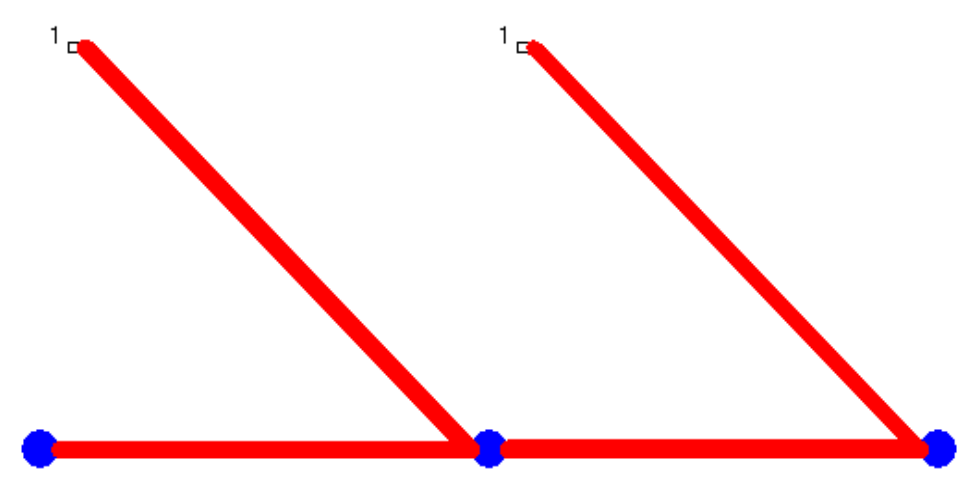

$\underline{\text { Input layer }} \quad \underline{\text { Hidden layer }} \quad \underline{\text { Output layer }}$

Fig. (1). Architecture of the neural network model used for estimating onset of precipitation of dissolved asphaltene in the solution of solvent + precipitant [1: Bias; •: Neuron; Output neuron: (mass of precipitant / mass of asphaltene); Input neuron: (mass of solvent / mass of asphaltene).

experimental data on onset of asphaltene precipitation. $V_{a}$ is calculated from density and molecular weight of asphaltene. For given $\delta_{a}, \Phi_{a}$ and temperature, the model only varies with $V_{m}$ and $\delta_{m}$.

As can be observed, thermodynamic models require considerable efforts to find an appropriate relationship for fitting experimental data, which can be eliminated by using artificial neural network technique.

\section{ARTIFICIAL NEURAL NETWORK MODEL}

The most commonly used ANNs are the feed-forward neural networks [42-48], which are designed with one input layer, one output layer and hidden layers [44-46, 48]. The number of neurons in the input and output layers equals to the number of inputs and outputs physical quantities, respectively [48]. In a $F N N$ model, the ideal number of neurons in the hidden layer(s) should be determined; few neurons produce a network with low precision and a higher number leads to overfitting and bad quality of interpolation and extrapolation [48]. The use of techniques such as Bayesian regularization, along with a Levenberg-Marquardt algorithm [40, 41], can help overcome this problem [42, 43, 48].

In the FNN model, the input layer of the network receives all the input data and introduces scaled data to the network [48]. The data from the input neurons are propagated through the network via weighted interconnections [48]. Every $i$ neuron in a $k$ layer is connected to every neuron in adjacent layers [48]. The $i$ neuron within the hidden $k$ layer performs the following tasks: summation of the arriving weighted inputs (input vector $I_{i}=\left[I_{i, 1}, \ldots I_{i, N k-1}\right]$ ) and propagations of the resulting summation through an activation function, $f$, to the adjacent neurons of the next hidden layer or to the output neu$\operatorname{ron}(\mathrm{s})$. In this work, the activation function is a linear function:

$f(x)=x$ where $x \in[0,1]$

where $x$ stands for parameter of linear activation function. A bias term, $b$, is associated with each interconnection in order to introduce a supplementary degree of freedom. The expres- sion of the weighted sum, $S$, to the $i^{\text {th }}$ neuron in the $k^{\text {th }}$ layer $(k \geq 2)$ is [48]:

$$
S_{k, i}=\sum_{j=1}^{N_{k-1}}\left[\left(w_{k-1, j, i} I_{k-1, j}\right)+b_{k, i}\right]
$$

where $w$ is the weight parameter between each neuronneuron interconnection. Using this feed-forward network with linear activation function, the output, $O$, of the $i$ neuron within the hidden $k$ layer is:

$$
O_{k, i}=S_{k, i}
$$

To develop the $A N N$, the data sets are generally subdivided into 3 classes: training, testing and validation [48]. After partitioning the data sets, the training set is used to adjust the parameters. All synaptic weights and biases are first initialized randomly. The network is then trained; its synaptic weights are adjusted by optimization algorithm, until it correctly emulates the input/output mapping, by minimizing the average root mean square error [48]. The optimization method chosen in this work was the Levenberg - Marquart algorithm [40, 41], as mentioned earlier. The testing set is used during the adjustment of the network's synaptic weights to evaluate the algorithms performance on

Table 3. Number of Neurons, Hidden Layers, Parameters, Data and Type of Activation Function Used in this Method

\begin{tabular}{|c|c|}
\hline Layer & Number of neurons \\
\hline \hline 1 & 1 \\
2 & 1 \\
3 & 1 \\
\hline
\end{tabular}

- $\quad$ Number of hidden layers $=1$.

- $\quad$ Number of parameters $=4$.

- Number of data used for training (and testing) $=40$.

- Type of activation function: linear.

- Input neurons: (mass of solvent/ mass of asphaltene).

- Output neuron: (mass of precipitant/ mass of asphaltene). 
Table 4. Experimental Values [14] and the Values Obtained Using the ANN Model for Mass Fraction of Precipitant in Synthetic Mixtures of Asphaltene + Solvent + Precipitant at Onset of Asphaltene Precipitation at 298.15 K and 0.1 MPa

\begin{tabular}{|c|c|c|c|c|c|c|c|}
\hline \multirow[b]{2}{*}{ Type of asphaltene } & \multirow[b]{2}{*}{ Precipitant } & \multirow[b]{2}{*}{ Solvent } & \multirow{2}{*}{$\begin{array}{l}\text { Mass fraction } \\
\text { of asphaltene }\end{array}$} & \multirow{2}{*}{$\begin{array}{c}\text { Mass fraction } \\
\text { of solvent }\end{array}$} & \multicolumn{3}{|c|}{ Mass fraction of precipitant } \\
\hline & & & & & $\begin{array}{c}\text { Experimental } \\
\text { value }\end{array}$ & $\begin{array}{c}\text { Value obtained using } \\
\text { the } A N N \text { model }\end{array}$ & $A D \%$ \\
\hline \multirow{20}{*}{ n-C5-Asphaltene } & \multirow{4}{*}{$\mathrm{n}-\mathrm{C} 5$} & \multirow{4}{*}{ Toluene } & 0.012 & 0.621 & 0.367 & $0.336^{*}$ & 8.4 \\
\hline & & & 0.008 & 0.623 & 0.369 & $0.376^{*}$ & 1.9 \\
\hline & & & 0.006 & 0.624 & 0.370 & $0.390 *$ & 5.4 \\
\hline & & & 0.003 & 0.594 & 0.403 & $0.399 *$ & 1.0 \\
\hline & \multirow{4}{*}{$\mathrm{n}-\mathrm{C} 5$} & \multirow{4}{*}{ Tetraline } & 0.010 & 0.513 & 0.477 & 0.480 & 0.6 \\
\hline & & & 0.007 & 0.513 & 0.480 & 0.476 & 0.8 \\
\hline & & & 0.005 & 0.515 & 0.480 & 0.480 & 0.0 \\
\hline & & & 0.002 & 0.518 & 0.480 & 0.480 & 0.0 \\
\hline & \multirow{4}{*}{$\mathrm{n}-\mathrm{C} 7$} & \multirow{4}{*}{ Toluene } & 0.011 & 0.569 & 0.420 & 0.429 & 2.1 \\
\hline & & & 0.008 & 0.570 & 0.422 & 0.424 & 0.5 \\
\hline & & & 0.006 & 0.571 & 0.423 & 0.420 & 0.7 \\
\hline & & & 0.002 & 0.576 & 0.422 & 0.422 & 0.0 \\
\hline & \multirow{4}{*}{$\mathrm{n}-\mathrm{C} 7$} & \multirow{4}{*}{ Tetraline } & 0.009 & 0.470 & 0.521 & 0.522 & 0.2 \\
\hline & & & 0.007 & 0.466 & 0.527 & 0.525 & 0.4 \\
\hline & & & 0.005 & 0.471 & 0.524 & 0.525 & 0.2 \\
\hline & & & 0.002 & 0.474 & 0.524 & 0.524 & 0.0 \\
\hline & \multirow{4}{*}{$\mathrm{n}-\mathrm{C} 10$} & \multirow{4}{*}{ Toluene } & 0.010 & 0.553 & 0.437 & 0.440 & 0.7 \\
\hline & & & 0.008 & 0.552 & 0.440 & 0.440 & 0.0 \\
\hline & & & 0.005 & 0.555 & 0.440 & 0.440 & 0.0 \\
\hline & & & 0.002 & 0.558 & 0.440 & 0.440 & 0.0 \\
\hline \multirow{24}{*}{ n-C7-Asphaltene } & \multirow{4}{*}{$\mathrm{n}-\mathrm{C} 5$} & \multirow{4}{*}{ Toluene } & 0.013 & 0.694 & 0.293 & 0.299 & 2.0 \\
\hline & & & 0.010 & 0.696 & 0.294 & 0.300 & 2.0 \\
\hline & & & 0.007 & 0.696 & 0.297 & 0.294 & 1.0 \\
\hline & & & 0.003 & 0.703 & 0.294 & 0.294 & 0.0 \\
\hline & \multirow{4}{*}{$\mathrm{n}-\mathrm{C} 5$} & \multirow{4}{*}{ Tetraline } & 0.011 & 0.562 & 0.427 & 0.429 & 0.5 \\
\hline & & & 0.008 & 0.562 & 0.430 & 0.440 & 2.3 \\
\hline & & & 0.005 & 0.550 & 0.445 & 0.435 & 2.2 \\
\hline & & & 0.002 & 0.554 & 0.444 & 0.444 & 0.0 \\
\hline & & & 0.012 & 0.636 & 0.352 & 0.324 & 8.0 \\
\hline & n $C 7$ & Tolun & 0.009 & 0.637 & 0.354 & 0.351 & 0.8 \\
\hline & $11-\mathrm{C}$ & Torductic & 0.006 & 0.639 & 0.355 & 0.378 & 6.5 \\
\hline & & & 0.003 & 0.608 & 0.389 & 0.384 & 1.3 \\
\hline & & & 0.010 & 0.509 & 0.481 & 0.470 & 2.3 \\
\hline & $n_{-} C 7$ & Tetraline & 0.007 & 0.499 & 0.494 & 0.490 & 0.8 \\
\hline & & 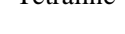 & 0.005 & 0.494 & 0.501 & 0.510 & 1.8 \\
\hline & & & 0.002 & 0.473 & 0.525 & 0.524 & 0.2 \\
\hline & & & 0.012 & 0.622 & 0.366 & 0.408 & 11.5 \\
\hline & $n$ & Tolиene & 0.008 & 0.585 & 0.407 & 0.392 & 3.7 \\
\hline & $11-C 10$ & 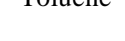 & 0.005 & 0.588 & 0.407 & 0.400 & 1.7 \\
\hline & & & 0.002 & 0.591 & 0.407 & 0.408 & 0.2 \\
\hline & & & 0.010 & 0.498 & 0.492 & 0.471 & 4.3 \\
\hline & $n-C 10$ & Tetraline & 0.007 & 0.497 & 0.496 & 0.514 & 3.6 \\
\hline & & & 0.005 & 0.475 & 0.520 & 0.518 & 0.4 \\
\hline & & & 0.002 & 0.456 & 0.542 & 0.542 & 0.0 \\
\hline
\end{tabular}

*: Obtained using validation step. 
the data not used for adjustment and stop the adjusting if the error on the testing set increases. Finally, the validation set measures the generalization ability of the model after the fitting process [48].

\section{RESULTS AND DISCUSSION}

The experimental data of Cimino et al. [14] are reported in Table 1. Table 2 reports the values for (mass of solvent / mass of asphaltene) and (mass of precipitant / mass of asphaltene), which have been used to developed the ANN method. The model shown in Fig. (1) and detailed in Table $\mathbf{3}$ with one hidden layer was used to calculate (mass of precipitant/ mass of asphaltene) as a function of (mass of solvent/ mass of asphaltene). It should be mentioned that plenty of data should generally be used for developing $A A N$ models, especially for highly non-linear systems. In our case, where the (mass of precipitant/ mass of asphaltene) is approximately linear function of (mass of solvent/ mass of asphaltene), few sets of data for training can be used to develop the $A N N$ model. However, the more data for training, the more reliable $A N N$ model results. Having this mind, one neuron in the hidden layer yielded acceptable results according to both the accuracy of the fit (minimum value of the objective function) and the predictive power of the neural network.

Tables 2 and $\mathbf{4}$ show the results obtained using the $A N N$ model developed in this work along with the absolute deviations $(A D)$. As can be seen in Table 4, the results obtained using the $A N N$ model for mass of precipitant in the solution of solvent + precipitant required to precipitate asphaltene are in acceptable agreement with the experimental data [14] reported in the literature. The results show less than $12 \%$ absolute deviation and the average absolute deviation (AAD) among all the experimental and estimated data is less than 2 $\%$. The deviations may be attributed to unreliability of some experimental data [14], as it is known that measuring onset of asphaltene precipitation, especially in dilute systems is one of the most difficult problems of oil analyses [32]. It should finally be mentioned that in the ANN model developed in this work, three parameters of the four parameters approach zero indicating that this $A N N$ model is approximately equivalent to a linear function.

\section{CONCLUSIONS}

A feed-forward artificial neural network model with one hidden layer that takes advantage of a modified LevenbergMarquardt optimization algorithm [40, 41], was developed for estimating onset of precipitation of dissolved asphaltenes in the solutions of solvent + precipitant. This model has one output neuron (mass of precipitant/ mass of asphaltene), one input neurons (mass of solvent/ mass of asphaltene) and one neuron in the hidden layer and uses a linear activation function. It was shown the experimental data reported in the literature [14] are well represented using this $A N N$ model.

\section{REFERENCES}

[1] J. G. Speight, The Chemistry and Technology of Petroleum. New York: Marcel Dekker, Inc, 1991.

[2] R. Cimino, S. Correra, A. Del Bianco, and T. P. Lockhart, "Solubility and phase behavior of asphaltenes in hydrocarbon media" Asphaltenes: Fundamentals and applications, E. Y. Sheu and O. C. Mullins (eds.), New York: Plenum Press, pp. 97-130, 1995.
[3] G. Porte, H. Zhou, and V. Lazzeri, "Reversible description of asphaltene colloidal association and precipitation", Langmuir, vol. 19/1, pp. 40-47, January 2003.

[4] F. I. Nellensteyn, "The colloidal structure of bitumens", The Science of Petroleum, Oxford University Press, London, vol. 4, pp. $2760,1938$.

[5] A. Firoozabadi, Thermodynamics of Hydrocarbon Reservoirs. First Edition, McGraw-Hill, 1999.

[6] IP 143/90 (Standard Number) Asphaltene (heptane insolubles) in petroleum products, standards for petroleum and its products, Institute of Petroleum, London, UK, pp. 143.1-143.7, 1985.

[7] S. I. Andersen and J. G. Speight, "Thermodynamic models for asphaltene solubility and precipitation”, J. Pet. Sci. Eng., vol. 22, pp. 53-66, January 1999.

[8] A. Hirschberg, L. N. J. DeJong, B. A. Schipper, and J. G. Meijer, "Influence of temperature and pressure on asphaltene flocculation", SPE J., vol. 24, pp. 283-293, June 1984.

[9] H. Rassamdana, B. Dabir, M. Nematy, M. Farhani, and M. Sahimi, "Asphalt flocculation and deposition: I. The onset of precipitation", AIChE J., vol. 42/1, pp. 10-22, January 1996.

[10] H. Rassamdana and M. Sahimi, "Asphalt flocculation and deposition: II. Formation and growth of fractal aggregates", AIChE J., vol. 42/12, pp. 3318-3332, December 1996.

[11] F. Chung, P. Sarathi, and R. Jones, "Modeling of asphaltene and wax precipitation", DOE, Topical Report No. NIPER-498, January 1991.

[12] K. J. Leontaritis, "Asphaltene deposition: A comprehensive description of problem manifestations and modeling approaches", SPE 18892, Presented at the SPE Production Operations Symposium, Oklahoma City, 13-14 March 1989.

[13] A. C. S. Ramos, C. C. Delgado, R. S. Mohamed, V. R. Almeida, and W. Loh, "Reversibility and inhibition of asphaltene precipitation in Brazilian crude oils", SPE 38967, Presented at the Latin American and Caribbean Petroleum Engineering Conference, Rio de Janeiro, Brazil, 30 August - 3 September 1997.

[14] R. Cimino, S. Correra, P. A. Sacomani, and C. Carniani, "Thermodynamic modelling for prediction of asphaltene deposition in live oils", SPE 28993, Presented at the SPE International Symposium on Oilfield Chemistry held in San Antonio, TX, USA, 14-17 February 1995.

[15] H. Pan and A. Firoozabadi, "Thermodynamic micellization model for asphaltene precipitation from reservoir crudes at high pressures and temperatures", SPE Prod. Fac., vol. 15/1, pp. 58-65, February 2000.

[16] H. Pan, A. Firoozabadi, and P. Fotland, "Pressure and composition effect on wax precipitation: Experimental data and model results", SPE Prod. Fac., vol. 12/4, pp. 250-258, November 1997.

[17] S. P. Godbole, K. J. Thele, and E. W. Reinbold, "EOS modeling and experimental observations of three-hydrocarbon-phase equilibria", SPE Res. Eng., vol. 10/2, pp. 101-108, May 1995.

[18] S. Kokal, J. Najman, S. Sayegh, and A. George, "Measurement and correlation of asphaltene precipitation from heavy oils by gas injection", J. Can. Pet. Tech., vol. 31/4, pp. 24-30, 1992.

[19] D. A. Storm, R. J. Barresi, and E. Y. Sheu, "Development of solid properties and thermochemistry of asphalt binders in the $25-65{ }^{\circ} \mathrm{C}$ temperature range", Energy Fuels, vol. 10/3, pp. 855 - 864, May 1996.

[20] N. E. Burke, R. E. Hobbs, and S. F. Kashou, "Measurement and modeling of asphaltene precipitation”, J. Pet. Tech., pp. 1440-1446, November 1990.

[21] S. Kawanaka, S. J. Park, and G. A. Mansoori, "The role of asphaltene deposition in EOR gas flooding: a predictive technique", SPE/DOE 17376, Presented at the SPE/DOE Enhanced Oil Recovery Symposium, Tulsa, Oklahoma, 17-20 April 1988.

[22] S. Kawanaka, S. J. Park, and G. A. Mansoori, "Organic deposition from reservoir fluids: A thermodynamic predictive technique", $S P E$ Res. Eng., pp. 185-192, May 1991.

[23] S. J. Park, A thermodynamic polydisperse polymer model: asphaltene flocculation, aggregation and deposition. Ph.D dissertation, University of Illinois, Chicago, USA, 1989.

[24] L. X. Nghiem, M. S. Hassam, R. Nutakki, and A. E. D. George, "Efficient modelling of asphaltene precipitation", SPE 26642, Presented at the SPE Annual Technical Conference and Exhibition, Houston, Texas, 3-6 October 1993.

[25] K. J. Leontaritis and G. A. Mansoori, "Asphaltene flocculation during oil production and processing: A thermodynamic colloidal 
model", SPE 16258, Presented at the SPE International Symposium on Oil field Chemistry, San Antonio, TX, 4-6 February 1987.

[26] A. I. Victorov and A. Firoozabadi, "Thermodynamic micellization model of asphaltene precipitation from petroleum fluids", AIChE J., vol. 42/6, pp. 1753-1764, June 1996.

[27] H. Pan and A. Firoozabadi, "A Thermodynamic micellization model for asphaltene precipitation: Part I: Micellar size and growth", SPE Prod. Fac., vol. 13/2, pp. 118-127, May 1998.

[28] H. Pan and A. Firoozabadi, "Complex multiphase equilibrium calculations by direct minimization of gibbs free energy by use of simulated annealing", SPE Res. Eval. Eng., vol. 11/1, pp. 36-42, February 1998.

[29] H. Pan and A. Firoozabadi, "Thermodynamic micellization model for asphaltene precipitation inhibition", AIChE J., vol. 46/2, pp. 416-426, February 2000.

[30] J. Z. Wu, J. M. Prausnitz, and A. Firoozabadi, "Molecularthermodynamic framework for asphaltene-oil equilibria", AIChE J., vol. 44/5, pp. 1188-1199, May 1998.

[31] J. Z. Wu, J. M. Prausnitz, and A. Firoozabadi, "Molecular thermodynamics of asphaltene precipitation in reservoir fluids", AIChE J., vol. 46/1, pp. 197-209, January 2000.

[32] A. K. M. Jamaluddin, J. Creek, C. S. Kabir, J. D. McFadden, D. D. Cruz, N. Joshi, and B. Ross, "A comparison of various laboratory techniques to measure thermodynamic asphaltene instability", SPE 72154, Presented at the SPE Asia Pacific Improved Oil Recovery Conference, Kuala Lumpur, Malaysia, 6-9 October 2001.

[33] S. I. Andersen and K. Potsch, "Solid organic deposition from a gas condensate field", AIChE National Spring Meeting, 14-18 March 1999.

[34] S. Thou, G. Ruthammer, and K. Potsch, "Detection of asphaltenes flocculation onset in a gas condensate system", SPE 78321, Presented at the SPE $13^{\text {th }}$ European Petroleum Conference, Aberdeen, Scotland, U.K, 29-31 October 2002.

[35] A. H. Mohammadi and D. Richon, "The Scott-Magat polymer theory for determining onset of precipitation of dissolved asphaltene in the solvent + precipitant solution", Open Therm. J., vol. 2, pp. 13-16, 2008.

[36] P. J. Flory, Principles of Polymer Chemistry. New York: Cornell University Press, 1953.

[37] R. L. Scott and M. Magat, "The thermodynamics of high-polymer solutions: I. The free energy of mixing of solvents and polymers of heterogeneous distribution", J. Chem. Phys., vol. 13/5, pp. 172177, May 1945.

[38] S. I. Sandler, Chemical and Engineering Thermodynamics. Third Edition, John Wiley \& Sons, 1999.

[39] B. E. Poling, J. M. Prausnitz, and R. Reid, Properties of Gases and Liquids. Fifth Edition, McGraw-Hill, 2000.

[40] D. Marquardt, "An algorithm for least-squares estimation of nonlinear parameters", SIAM J. Appl. Math., vol. 11/2, pp. 431-441, 1963.

[41] K. Levenberg, "A method for the solution of certain problems in least squares", Quart. Appl. Math., vol. 2, pp. 164-168, 1944.

[42] F. Rivollet, Etude des propriétés volumétriques (PVT) d'hydrocarbures légers (C1-C4), du dioxyde de carbone et de l'hydrogène sulfuré: Mesures par densimétrie à tube vibrant et modélisation. PhD Thesis, Paris School of Mines, France, December 2005 (In French).

[43] B. Wilamowski, S. Iplikci, O. Kayank, and M. O. Efe, International Joint Conference on Neural Networks (IJCNN'01) pp. 1778-1782, Washington DC, 15-19 July 2001.

[44] A. Chouai, S. Laugier, and D. Richon, "Modeling of thermodynamic properties using neural networks: Application to refrigerants", Fluid Phase Equilib., vol. 199, pp. 53-62, 2002.

[45] L. Piazza, G. Scalabrin, P. Marchi, and D. Richon, "Enhancement of the extended corresponding states techniques for thermodynamic modelling. I. Pure fluids", Int. J. Refrig., vol. 29/7, pp. 1182-1194, 2006.

[46] G. Scalabrin, P. Marchi, L. Bettio, and D. Richon, "Enhancement of the extended corresponding states techniques for thermodynamic modelling. II. Mixtures”, Int. J. Refrig., vol. 29/7, pp. 1195-1207, 2006.

[47] J. E. Schmitz, R. J. Zemp, and M. J. Mendes, "Artificial neural networks for the solution of the phase stability problem", Fluid Phase Equilib., vol. 245, pp. 83-87, 2006.

[48] A. Chapoy, A. H. Mohammadi, and D. Richon, "Predicting the hydrate stability zones of natural gases using artificial neural networks", Oil Gas Sci. Technol. Rev. IFP, vol. 62/5, pp. 701-706, 2007.

(C) Mohammadi and Richon; Licensee Bentham Open.

This is an open access article distributed under the terms of the Creative Commons Attribution License (http://creativecommons.org/licenses/by/2.5/), which permits unrestrictive use, distribution, and reproduction in any medium, provided the original work is properly cited. 